Mundo Agrario vol. 18, no 38, e052, agosto 2017. ISSN 1515-5994

Universidad Nacional de La Plata.

Facultad de Humanidades y Ciencias de la Educación.

Centro de Historia Argentina y Americana

\title{
Las dos caras de la moneda: El impacto de la migración europea en la campaña de Buenos Aires, San Vicente y Almirante Brown (1869-1895)
}

\begin{abstract}
The Two Sides of the Coin: The Impact of European Migration in the Buenos Aires Countryside, San Vicente and Almirante Brown (18691895)
\end{abstract}

\section{Claudia Contente *}

* Universitat Pompeu Fabra, España | claudia.contente@upf.edu

\section{PALABRAS CLAVE}

Historia rural

Campaña de Buenos Aires

Censos

Migraciones

Siglo XIX

\section{KEYWORDS}

Rural History

Countryside of Buenos Aires

Census

Migrations

Nineteenth century

\section{RESUMEN}

A partir de las cédulas censales del Primer y Segundo Censo Nacional Argentino (1869 y 1895) se analiza la población y actividades productivas del partido de San Vicente (provincia de Buenos Aires) y de Almirante Brown en 1895. Esta última jurisdicción que fue creada en 1873, en parte a expensas de San Vicente. Exploraremos la evolución entre ambas fechas de la composición de la población en términos generales y de las diferentes comunidades, así como de las actividades que desempeñaban sus miembros, prestando particular atención a las actividades agrícolas. Veremos algunos de los cambios que conoció la zona en ese periodo y el impacto que representó la migración que, más allá de los ya bien conocidos e innegables beneficios que aportó, tuvo igualmente repercusiones contrastadas para algunos sectores de la población local.

\section{ABSTRACT}

We analyze the population and the production activities of the jurisdictions of San Vicente (Buenos Aires Province) and Almirante Brown, the latter created in 1873 partially at the expense of San Vicente, in 1895. We carry out this analysis using the original census records of the First and the Second Argentine National Census (1869 and 1895). We will explore the evolution of the population between both dates in general terms and in terms of the different communities, as well as in terms of the activities of their members, paying particular attention to the agricultural activities. We will see some of the changes that the area underwent during that period and the impact of the migration that, apart from the already well known and undeniable benefits, had contrasting repercussions on some sectors of the local population. 
Desde la fundación misma de la ciudad, Buenos Aires conoció un fuerte crecimiento demográfico sustentado en buena medida por la llegada de migrantes. Aunque hubo importantes variaciones en cuanto a la intensidad, los orígenes y motivaciones de quienes llegaban, la migración ha sido una presencia estable a lo largo de su historia. Si en sus orígenes las actividades mercantiles supieron atraer pobladores de Portugal, de otras zonas del virreinato, o de ultramar (González Lebrero, 2002, pp. 86 y ss), con el tiempo, el desarrollo de las actividades agrícolas sería igualmente un estímulo para atraer nuevos habitantes. Así, fueron básicamente los migrantes quienes contribuyeron a poblar la región haciendo retroceder la frontera del territorio controlado por los indios, ya fuera por iniciativa personal o en el marco de acciones emprendidas por el estado (Mateo 2013; Ratto 2003, 2013; Ortelli, 2012). A principios del siglo XIX, estos migrantes provenían esencialmente de otras regiones del virreinato. Hacia 1830, comenzó a diversificarse la procedencia y a aumentar la afluencia de origen europeo que, de a poco, pasó a predominar ampliamente sobre la tradicional “micromigración” regional (Massé, 2006; Ceva, 2012, p. 313). Este aumento progresivo de la migración a partir de la década de 1830 representa un hecho notable, dados los tiempos convulsos que, desde un punto de vista político, se vivían en la región. Unos veinte años más tarde, a partir de la década de 1850 y aún en tiempos signados por el caos político, el auge de la producción agrícola, las perspectivas económicas favorables y las acciones concretas del estado llevaron a consolidar esta corriente migratoria que alcanzaría su punto máximo a principios del siglo XX.

De esta manera, si según las listas nominativas, en 1815 el 9,5 \% de los habitantes de la campaña bonaerense eran originarios de otras provincias (GIHRR, 2004), en 1869 este índice era aún del 8 \%, mientras que los extranjeros representaban, ya en ese momento, 19,2 \% de los residentes en Buenos Aires ${ }^{\underline{1}}$, para alcanzar el 30,6 \% en 1895 (Massé, 2012; Lattes y Andrada, 2012, p. 196)

El primer censo nacional de población (1869) tuvo un significado muy particular para la Argentina ya que hacía muy poco tiempo que el país se había reunificado tras largos años de guerras civiles y conflictos de todo tipo. Uno de los primeros pasos para consolidar el estado era conocer mejor el territorio, la población y su distribución en el espacio. De manera que el censo fue pensado cuidadosamente y representó un esfuerzo considerable de organización que, además de permitir estos objetivos mencionados, contribuía de manera sutil a forjar los cimientos de un sentimiento de pertenencia nacional (Otero, 2006)

La población argentina en su conjunto puede ser descrita para 1869 como una sociedad típica del Antiguo Régimen, en cuanto a equilibrio de sexos, importante proporción de niños debido a la fecundidad natural, y rápida disminución del tamaño de los grupos en las cohortes subsiguientes debida a la fuerte incidencia de la mortalidad. Sin embargo, si observamos por regiones, la relación de masculinidad en Buenos Aires y el litoral es muy superior a la del interior del país, en especial a la del noroeste. En otras palabras, el interior expulsa población masculina que recibe la zona del Litoral. A esta población nacida en argentina que se distribuía de manera desigual en el territorio se agregaron los extranjeros, sobre todo hombres mayores de 15 años, lo que acentuó aún más este desequilibrio.

El siguiente censo nacional tuvo lugar en 1895, de modo tal que nos basaremos en estas dos "fotos" para obtener una visión global de la evolución de una zona de la campaña bonaerense, la del partido de San Vicente en 1869, y la de San Vicente y Almirante Brown en 1895. Se trata de los primeros resultados obtenidos de una investigación actualmente en curso en la que exploraremos la composición de la población en su conjunto y de las diferentes comunidades, así como de las actividades que desempeñaban sus miembros, en particular en las tareas relacionadas con el mundo agrícola. De esta manera, veremos algunos de los cambios que conoció la zona en ese periodo y el impacto que representó la migración que, más allá de los ya bien conocidos e innegables beneficios que aportó, implicó igualmente repercusiones no tan claramente positivas para algunos sectores de la población local.

\section{San Vicente a grandes rasgos}

San Vicente es un pago agropecuario rural situado a unos $50 \mathrm{~km}$ al sur de la ciudad de Buenos Aires. Los primeros 
libros parroquiales de San Vicente datan de 1780, de ahí que esa sea la fecha atribuida a su fundación, si bien se sabe que había ya habitantes “cristianos” instalados en la zona desde hacía varias décadas. En ese entonces se conocía por San Vicente una vasta zona, con límites muy poco precisos y una superficie estimada en unos 8.000 $\mathrm{km}^{2}$ (Levene 1941, pp. 641-646). A partir de 1822 comenzaron las reorganizaciones administrativas y se crearon varios partidos a costa de su jurisdicción que, en 1869, era de unos $1.200 \mathrm{~km}^{2} \underline{2}$. Para 1895, fecha del segundo censo que analizaremos aquí, se le había amputado una nueva fracción, que contribuiría a formar el partido de Almirante Brown (1873), para cuya creación se recortarían igualmente -y en mayor proporción- los vecinos partidos de Quilmes y Lomas de Zamora. Mientras el espacio bajo la jurisdicción de San Vicente se iba encogiendo, la población crecía muy rápidamente; en 1815 vivían allí 4.376 habitantes, en 1869 eran 4.249 , mientras que en 1895 el pago registraba 7.442 habitantes. Almirante Brown, por su parte, contaba con 5.738 pobladores para sus aproximadamente $130 \mathrm{~km}^{2}$.

\section{Mapa 1}

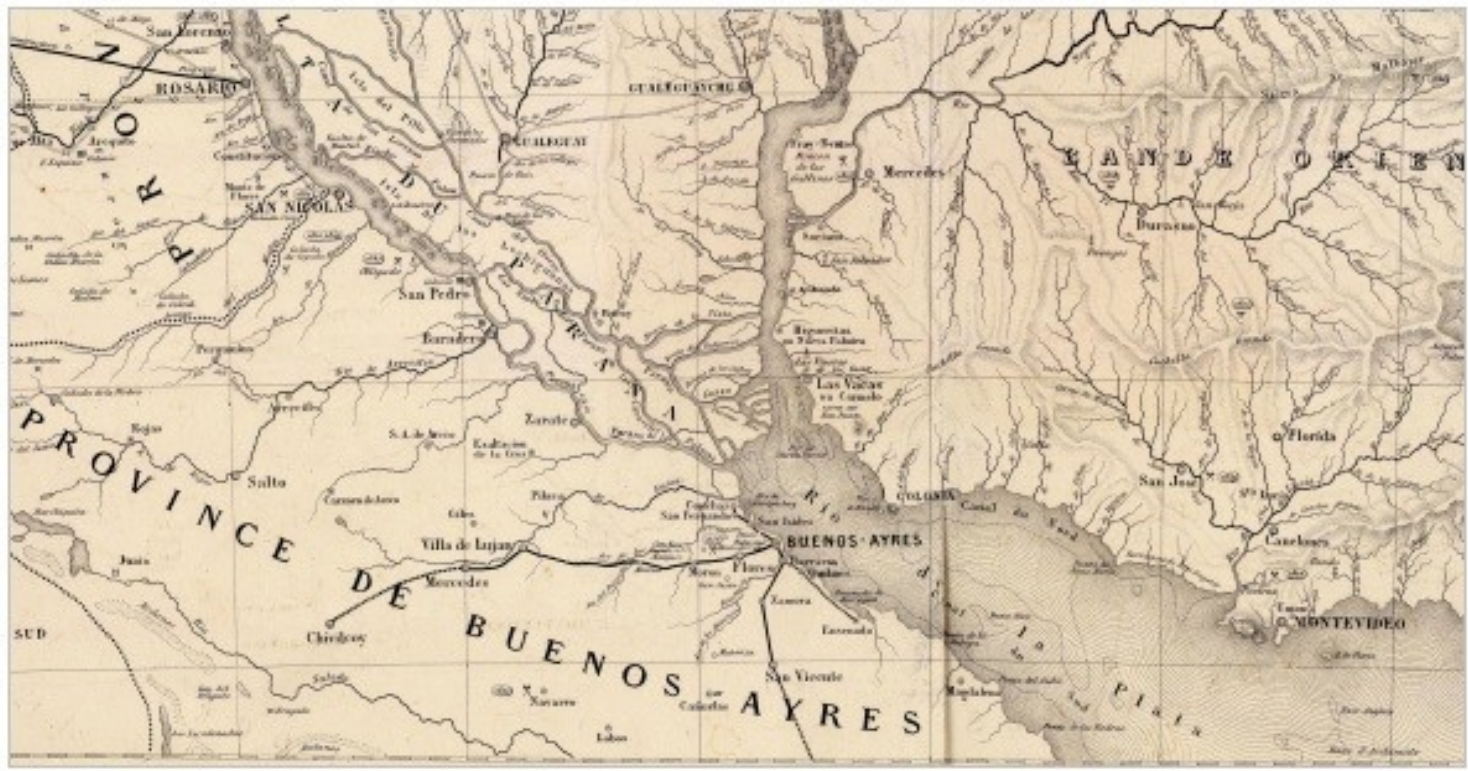

Fuente Description géographique et statistique de la Conféderation Argentine par V. Martin de Moussy. Deuxième édition atlas, Paris, Librairie de Firmin Didot Frères, Fils et Cie. Imprimeurs de l’Institut, 1873, Planche VIII.

\section{Cuadro 1 - Población de San Vicente, 1869, y de San Vicente y Almirante Brown, 1895}

\begin{tabular}{|l|c|c|c|c|}
\hline & \multicolumn{2}{|l|}{ San Vicente 1869 } & \multicolumn{2}{l|}{ San Vicente y Alte. Brown 1895 } \\
\hline & Población Total & $\begin{array}{c}\text { Índice de } \\
\text { masculinidad }\end{array}$ & Población Total & $\begin{array}{c}\text { Índice de } \\
\text { masculinidad }\end{array}$ \\
\cline { 1 - 4 } Hombres & 2.079 & \multirow{2}{*}{119,2} & 7.500 & \multirow{2}{*}{118,9} \\
\cline { 1 - 3 } Mujeres & 1.744 & & 6.307 & \\
\cline { 1 - 2 } Total & 3.823 & & 13.807 & \\
\hline
\end{tabular}

Estos cambios implican que, si bien se trata de la misma área geográfica, las superficies de las jurisdicciones estudiadas no coinciden, de modo que es técnicamente imposible una comparación minuciosa entre los dos momentos. Sin embargo, podremos apreciar algunas transformaciones y tendencias sin perder de vista que al 
incluir Almirante Brown estamos incorporando igualmente áreas que San Vicente no abarcaba en 1869.

Es importante señalar igualmente que, si bien los censos representan una fuente de un valor inestimable para reconstruir el conjunto de la población, los datos que proporcionan no suelen tener la precisión que suponemos en la actualidad. En algunos casos, somos nosotros los que no estamos en condiciones de descifrar qué se esconde realmente detrás de las categorías inscritas que respondían a una grilla propia de las preguntas, las preocupaciones de los contemporáneos (Otero 2006, pp. 252-262), que podían parecer muy claras y evidentes a ojos de quien las registró pero no siempre lo son del todo para nosotros.

\section{Los pobladores y sus actividades}

A mediados del siglo XIX la ganadería seguía siendo el sector más dinámico de la economía argentina, aunque las lanas ya estaban remplazando a los cueros bovinos en la cúspide de las exportaciones, y serían a su vez desplazadas por cereales y bovinos hacia fines del siglo (ver, por ejemplo, Miguez, 2008; Hora, 2010 y 2012, pp. 145-181; Rayes, 2015; Barsky y Gelman, 2001). La provincia de Buenos Aires, gracias a esta coyuntura económica particularmente próspera que requería abundante mano de obra, era un destino atractivo para los nuevos pobladores. En 1869, San Vicente comenzaba a consolidar su especialización como productor de lana, lo que había atraído a migrantes provenientes de Irlanda, Escocia e Inglaterra, que encontramos en grupos familiares a menudo bien instalados, a la cabeza de explotaciones consolidadas. La cría de ovejas no implicó que se abandonara el ganado vacuno y menos aún la producción lechera y los cereales que se cultivaban allí desde que se poblara la región y que iban a tomar impulso en las décadas siguientes. A partir de 1865 llegó a San Vicente la línea del ferrocarril que unía Buenos Aires con Chascomús, un factor que mejoró sustancialmente la salida de sus productos y sus perspectivas.

Si, como mencionamos, en 1869 los extranjeros representaban un 19,2 \% de los habitantes de la provincia, en San Vicente alcanzaban el 24,7 \% de los residentes. En 1895, 27,6 \% de la población de San Vicente y el 40,1 \% de la de Almirante Brown -más cercana a la ciudad de Buenos Aires- había nacido fuera del territorio nacional 3 . Recordemos que la proporción de extranjeros era entonces de casi 31 \% para el conjunto de la provincia de Buenos Aires, excluida la capital que contaba un $52 \%$ de migrantes 4 .

Figura 1a - Población de San Vicente, 1869

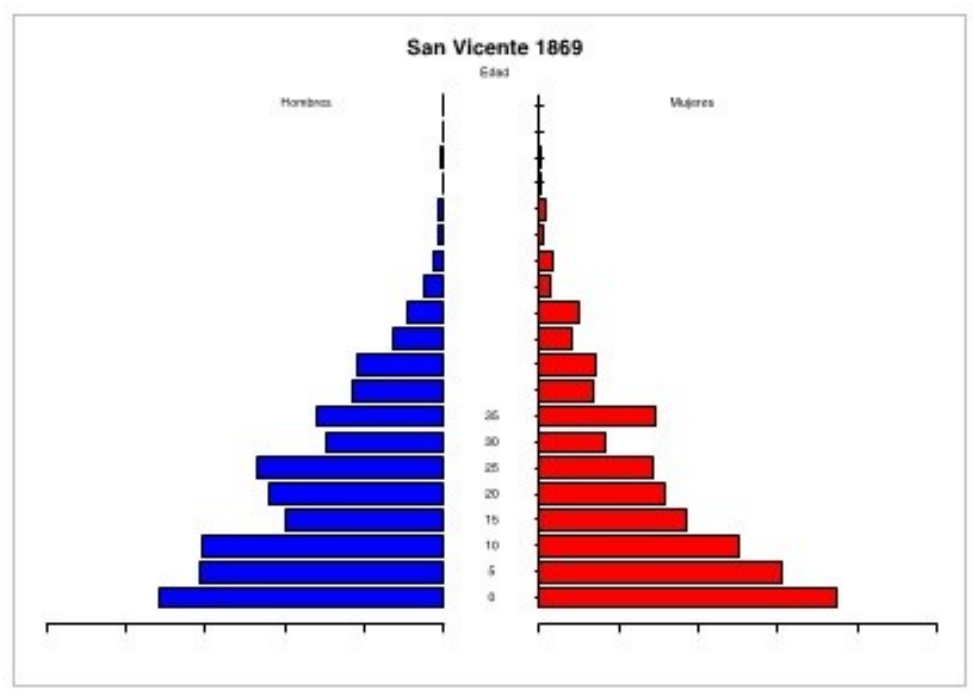


Figura 1b - Población de San Vicente y Almirante Brown, 1895

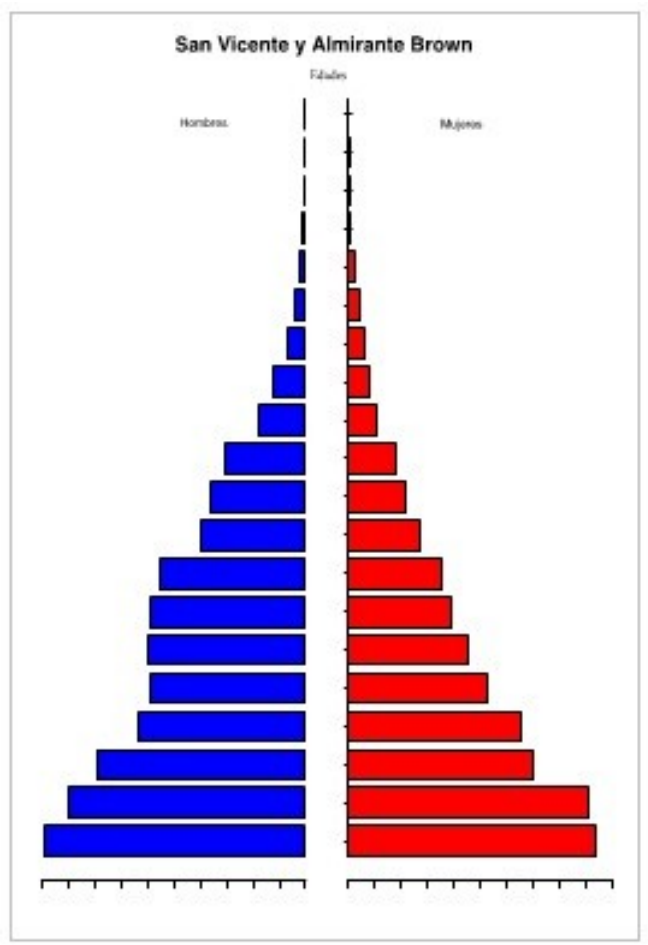

También en lo que respecta a los índices de masculinidad (la proporción de hombres con respecto a las mujeres), San Vicente estaba por encima de la media de la provincia de Buenos Aires -113 en 1895- (Schkolnik y Pantalides, 1974, p. 70). Estos índices son similares en los dos censos (cuadro 1), con un neto predominio de los varones en ambos, sin embargo, esconden situaciones diferentes.

La pirámide de población de los nativos, en 1869 (figura 2), muestra un vacío entre los hombres de entre 20 y 50 años debido por una parte a la sobremortalidad producida tanto por los conflictos armados de los años precedentes como la Guerra del Paraguay que tiene lugar en el mismo momento en que se registra el censo (1864-1870); muchos de esos hombres estarían en ese entonces combatiendo, mientras que los extranjeros estaban eximidos de participar en las milicias (Contente y Barcos, 2016, pp. 9-12). Por otra parte, las oportunidades de emprender que se ofrecían en zonas más alejadas sin duda estaban drenando hombres hacia esas zonas; es probable que una parte de los hombres argentinos ausentes en 1869 estuvieran en el sur participando en la expansión de la frontera y en la economía ganadera, en busca de nuevas oportunidades (Mateo, 1993; Canedo, 2000; Santilli, 2010).

Figura 2 - Pirámide de población: argentinos en San Vicente, 1869

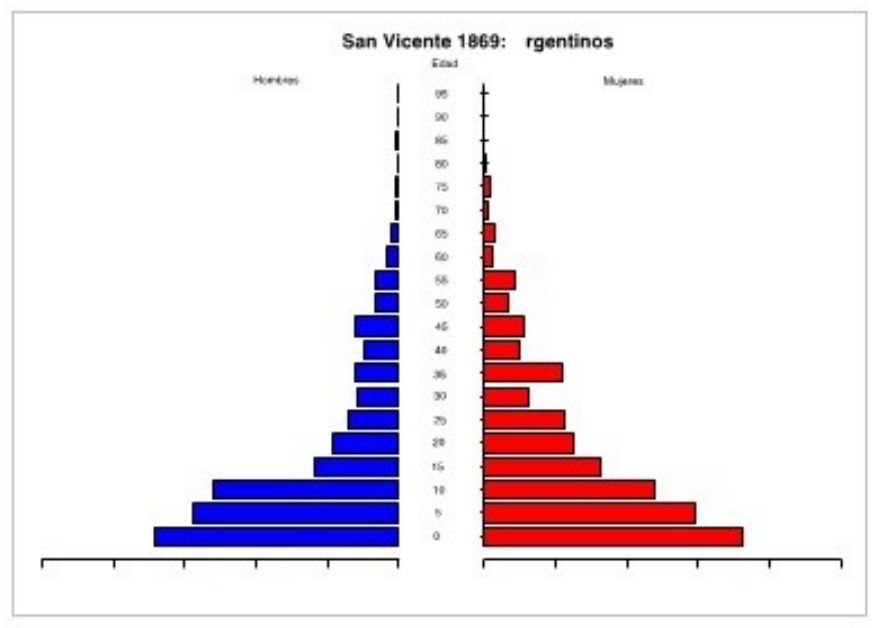


Dado que los migrantes eran hombres en su mayoría, su distribución sobre el territorio de la provincia de Buenos Aires - directamente vinculada con oportunidades laborales o cadenas migratorias- era desigual. Así, mientras en 1869 el índice de masculinidad en San Vicente entre los argentinos era de 87, entre los nacidos en el extranjero era de $332^{5}$. En otros términos, los recién llegados no solo compensaban ampliamente la falta de hombres nativos como consecuencia de todos estos factores, sino que, sin duda, esta coyuntura facilitó para algunos de ellos las posibilidades de hacerse un lugar en la sociedad local, y de cubrir las necesidades que la falta de hombres pudiera producir en las explotaciones, en el mejor de los casos, casándose con alguna viuda que tuviera ya una explotación en marcha, o alguna joven que le facilitara la inserción en la sociedad local $\underline{6}$.

Se observa que 26 años después, en 1895, este desequilibrio entre los sexos de los nacidos en el país ya está en vías de reabsorberse (cuadro 2). Cabe aclarar que los hijos de los inmigrantes, al ser automáticamente argentinos, también habrían contribuido a restablecer cierto equilibrio. Sólo a partir del censo de 1914 se registrará equilibrio entre los sexos de la población nativa (Schkolnik y Pantalides, 1974, p. 73)

Entre los migrantes, si bien la población masculina sigue siendo amplia mayoría en 1895, la proporción de mujeres ha aumentado relativamente y el índice de masculinidad ha tenido un fuerte descenso, lo que da la pauta de una migración que implica cada vez más a familias y ya no a hombres solos en la misma medida que antes, en otras palabras, una corriente migratoria que se consolida.

En todo caso, el desequilibrio demográfico implicaba que hubiera una considerable proporción de hombres solteros de más de 21 años, y que solo unas pocas mujeres lo fueran (cuadro 3). Implicaba igualmente que en la zona fueran a menudo los hombres argentinos quienes encontraran mayores dificultades para encontrar esposa (Contente, 2014).

Cuadro 2 - San Vicente 1869, San Vicente y Almirante Brown 1895: Índices de masculinidad

\begin{tabular}{|l|c|c|}
\hline & $\begin{array}{c}\text { San Vicente } \\
1869\end{array}$ & San Vicente y Almte. Brown 1895 \\
\hline Argentinos & 87 & 100 \\
\hline Extranjeros & 332 & 198 \\
\hline
\end{tabular}

\section{Cuadro 3 - San Vicente, 1869; San Vicente y Almirante Brown, 1895: Solteros mayores de 21 años (porcentaje)}

\begin{tabular}{|c|c|c|}
\hline & San Vicente 1869 & San Vicente y Almte. Brown 1895 \\
\hline Hombres & 47 & 41 \\
\hline Mujeres & 26 & 20 \\
\hline
\end{tabular}

La consigna para ambos censos fue registrar las actividades profesionales de los mayores de 14 años, de modo que es esta la fracción de la población en la que hemos basado nuestros cálculos y a la que nos referimos concretamente al evocar el mundo del trabajo. No cabe duda de que los menores participaban en las tareas del grupo doméstico. De hecho, suelen realizar actividades que pueden eventualmente ser complementarias de las del jefe de familia, como alguna niña cocinera o un niño boyero (encargado de bueyes), lo que confirma lo evidente: aunque ya las autoridades intentaran que al menos hasta los 14 años los niños fueran a la escuela, la gran mayoría colaboraba en la medida de sus posibilidades con las actividades familiares.

Hay que tener presente que la ocupación que se anotaba no excluía que existieran otras. A menudo se combinaban diversas actividades, sobre todo en zonas rurales; entendemos que el censista anotó aquella que consideraba predominante o que le declararon como tal, lo que no impedía, por ejemplo, al labrador criar igualmente animales. 
En todo caso, la proporción entre hombres y mujeres que componen la fuerza de trabajo no parece haber variado de manera significativa entre ambas fechas: si en 1869 de cinco trabajadores cuatro eran hombres y una era mujer, en 1895 la proporción era aproximadamente la misma.

\section{Cuadro 4 - San Vicente, 1869; San Vicente y Almirante Brown, 1895: \\ Población potencialmente activa y que declara una actividad ${ }^{7}$}

\begin{tabular}{|l|c|c|c|c|c|c|c|c|}
\hline & \multicolumn{4}{|c|}{ San Vicente 1869 $\underline{3}$ San Vicente y Almte. Brown 1895} \\
\hline & $\begin{array}{c}\text { + de 14 } \\
\text { años }\end{array}$ & $\%$ & $\begin{array}{c}\text { Con } \\
\text { activ. }\end{array}$ & $\%$ & $\begin{array}{c}\text { + de 14 } \\
\text { años }\end{array}$ & $\%$ & $\begin{array}{c}\text { Con } \\
\text { activ. }\end{array}$ & $\%$ \\
\hline Hombres & 1.311 & 56,9 & 1.164 & 80,8 & 4.788 & 55,9 & 4.108 & 77,8 \\
\hline Mujeres & 994 & 43,1 & 276 & 19,2 & 3.782 & 44,1 & 1.175 & 22,2 \\
\hline Total & 2.305 & 100 & 1.440 & 100 & 8.570 & 100 & 5.283 & 100 \\
\hline
\end{tabular}

* con activ.: declaran una actividad

Respecto a las ocupaciones de las mujeres, nos limitaremos a decir aquí que a fines del siglo XIX, al igual que en 1869 (Contente, 2010; Contente y Barcos, 2015), dos tercios declaraban ganarse la vida gracias a actividades domésticas como lavar, planchar, coser o cocinar, actividades que podían realizarse en la casa sin descuidar la propia familia. Es en el tercio restante que se percibe una evolución: paulatinamente adquieren más importancia entre ellas otro tipo de actividades como las ligadas a la educación y al comercio.

Observamos igualmente que a fines de siglo ha disminuido ligeramente la proporción de hombres que declaran trabajar y ha aumentado la de las mujeres (cuadro 4). Nuestra hipótesis es que esto probablemente no refleja un cambio real sino simplemente un cambio en el registro ligado a la percepción que los censistas tenían de la realidad. Sin duda, la mayoría - si no todas las mujeres - trabajaban tanto en el medio rural como en los pueblos. La diferencia es que, como veremos, un claro proceso de urbanización se había instalado en el conjunto de la provincia de Buenos Aires, al que no escapaba nuestra zona: mientras que las tareas relacionadas con los quehaceres propios de la explotación familiar parecían obvias y no daban lugar a una retribución -por ende el censista no solía registrarlas-, las actividades comerciales y artesanales, que son mucho más frecuentes en 1895, eran en cambio más visibles y sí generaban una remuneración específica, de ahí que se las consignara por escrito.

\section{Las actividades masculinas}

Si echamos una mirada a la evolución de las ocupaciones registradas entre los hombres llama la atención, como adelantábamos, el avance de las actividades que suelen predominar en aglomeraciones urbanas (como sastres, zapateros, peluqueros, fondas... $)^{\underline{9}}$, y el consiguiente retroceso de aquellas previsibles en zonas rurales (ver figura 3).

Si en 1869 el 83,3 \% de la población masculina se dedicaba a las tareas agrícolas, en 1895 este porcentaje no llega al 57 \%. Más aún, es factible que este porcentaje probablemente sea aún menor porque en 1895 hay unos cuantos industriales pero no constan obreros, categoría que la grilla de ocupaciones no contemplaba. De modo que es probable que al menos parte de los obreros en cuestión estén incluidos entre los jornaleros y, en consecuencia, entre los trabajadores agrícolas.

Ya en 1869, la variedad de oficios y actividades sugería un pueblo dinámico y próspero $\underline{10}$, 26 años después han hecho su aparición entre los habitantes empleados de banco, de correos, municipales, de registro civil (en 1886 el estado comenzó a llevar el registro de nacimientos, matrimonios y muertes), todo lo cual pone en evidencia la 
creciente presencia del estado en la zona mediante el desarrollo de sus instituciones. Gracias a la bonanza económica y el progreso tecnológico que se vivía en esos tiempos también han hecho irrupción otras actividades como tipógrafos, electricistas, fotógrafos, etc. Progreso que, como veremos, está en buena medida sustentado por el savoir faire que traen consigo algunos de estos recién llegados desde horizontes lejanos.

\section{Figura 3 - San Vicente, 1869; San Vicente y Almirante Brown, 1895: Sectores de actividad de la población masculina}

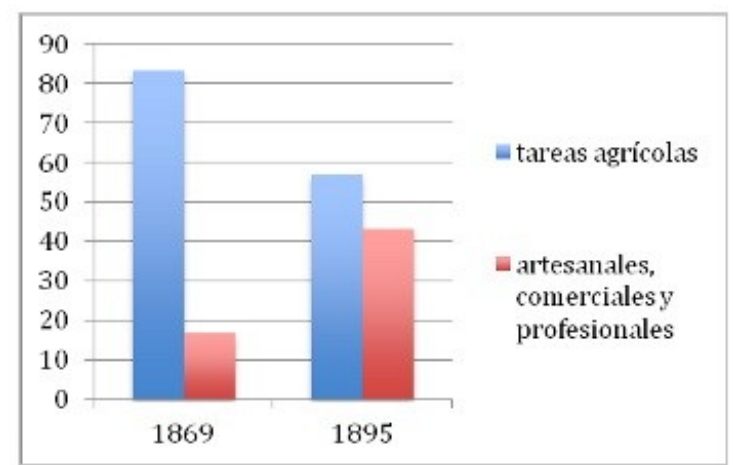

En 1869 en San Vicente 85 \% de las casas eran de adobe y solo había unas pocas casas de material concentradas en el pueblo y en una zona muy precisa de la jurisdicción. La presencia de 16 albañiles, 8 carpinteros y cuatro herreros, la mayoría de ellos extranjeros, sugería que este aspecto estaba cambiando y que se estaba edificando. En las décadas siguientes esta cifra creció exponencialmente: más allá del sesgo que representa estar considerando superficies que no se corresponden con exactitud, constatamos que, si la población entre ambos partidos se ha multiplicado por 3,6 en el periodo estudiando, la cantidad de albañiles, carpinteros y herreros se multiplicó entretanto por $10^{\underline{11}}$.

\section{Nativos y migrantes}

La cercanía y poderosa influencia de la ciudad de Buenos Aires es claramente uno de los factores que da cuenta de ese acelerado proceso de urbanización y, obviamente, el fuerte caudal migratorio recibido por la zona también es un ingrediente de peso: En 1895, 60 \% de los hombres potencialmente activos (de 14 y más años, según la consigna del censo) eran de origen extranjero y estaban presentes en todos los rubros de actividades (ver cuadro 5).

Veamos en primer lugar cómo evolucionó globalmente el peso de las diferentes comunidades en el mercado de trabajo en el periodo:

\section{Cuadro 5 - Origen de la población masculina de 14 y más años que declara una ocupación}

\begin{tabular}{|l|c|c|c|c|}
\hline & \multicolumn{2}{|c|}{1869} & \multicolumn{2}{c|}{1895} \\
\hline & cantidad & $\%$ & cantidad & $\%$ \\
\hline Argentinos & 506 & 43,5 & 1.498 & 36,5 \\
\hline Italianos & 295 & 25,3 & 1.400 & 34,1 \\
\hline Españoles & 128 & 11 & 537 & 13,1 \\
\hline Franceses & 124 & 10,6 & 418 & 10,2 \\
\hline Otros orígenes & 111 & 9,5 & 255 & 6,1 \\
\hline Total & 1.164 & 100 & 4.108 & 100 \\
\hline
\end{tabular}


Ante todo, hemos visto que para 1895 la población nativa se había recuperado parcialmente de las pérdidas sufridas en las décadas anteriores, sin embargo, ha perdido peso relativo dentro del conjunto de los trabajadores. Italianos y españoles, cuyas corrientes migratorias se han intensificado en el periodo, muestran en cambio una presencia más importante a fines de siglo (cuadro 5) $\underline{12}$. La presencia de cada grupo en los diferentes sectores de actividades también ha evolucionado a lo largo de estas décadas.

\section{Cuadro 6 - Actividades según las comunidades de origen (en porcentajes)}

\begin{tabular}{|l|c|c|c|c|c|c|c|c|}
\hline & \multicolumn{2}{|c|}{ Argentinos } & \multicolumn{2}{c|}{ Italianos } & \multicolumn{2}{c|}{ Españoles } & \multicolumn{2}{c|}{ Franceses } \\
\hline & 1869 & 1895 & 1869 & 1895 & 1869 & 1895 & 1869 & 1895 \\
\hline \% de los trabajadores & 43,5 & 36,4 & 25,3 & 34,1 & 11 & 13,1 & 10,6 & 10,2 \\
\hline Hombres con activ. atribuida & 506 & 1.496 & 295 & 1.400 & 128 & 537 & 124 & 418 \\
\hline Hacendados, estancieros & 26,1 & 5,7 & 0,7 & 0,6 & 8,6 & 3,7 & 4,8 & 2,6 \\
\hline Labrad., chacareros & 3,4 & 5,3 & 22 & 11,1 & 5,5 & 6,1 & 8,1 & 5,5 \\
\hline Jornaleros y peones & 48 & 40 & 46,9 & 36,3 & 48,4 & 38,4 & 46,8 & 26,5 \\
\hline Comercio & 3 & 9,4 & 5,4 & 8,3 & 8,1 & 11,9 & 10,2 & 7,7 \\
\hline Construcción & 0,6 & 2,4 & 5,8 & 15,8 & 6,3 & 4,5 & 2,4 & 3,3 \\
\hline Otras actividades & 18,9 & 37,2 & 19,2 & 27,9 & 23,1 & 35,4 & 27,7 & 54,4 \\
\hline Total: & 100 & 100 & 100 & 100 & 100 & 100 & 100 & 100 \\
\hline
\end{tabular}

Todas las comunidades han visto disminuir relativamente la proporción de trabajadores en las actividades agrícolas. Si miramos en detalle, esta disminución ha sido importante en la cría de ganado mientras que para aquellos que se dedicaban sobre todo al cultivo de cereales no se observa una tendencia clara. Hay asimismo menos peones y jornaleros, aunque siguen representando una ocupación que acapara a buena parte de los trabajadores $\underline{13}$.

Las otras actividades, el comercio y la construcción han conocido, en cambio, un crecimiento notable.

Hemos incluido aquí a los funcionarios públicos (en su mayoría argentinos), prácticamente inexistentes en 1869 y a un importante universo de empleados que representan un problema metodológico, ya que, si bien para algunos explicita el área (de ferrocarril, de telégrafo, de registro civil, municipal, etc.), en la mayoría de los casos se trata de empleado a secas, por lo que queda la duda de si podrían inscribirse igualmente en otro sector; quizás algún censista podría, por ejemplo, registrar como empleado a alguien que se desempeñara en el comercio.

Este es un sector muy vasto ya que entre las otras actividades están incluidos además profesionales como médicos, maestros o escribanos, los artesanos (sastre, zapatero, etc.). En 1895 han aparecido industriales (sin más precisión) que mencionábamos más arriba y pequeños productores como queseros o cerveceros que también hemos incluido en este grupo.

Es justamente en este grupo de otros que se concentra la mayoría de las profesiones de los miembros de la comunidad francesa, con sus numerosos “industriales” y artesanos. Mientras que para los españoles solo se destacan -y muy relativamente- las ocupaciones relacionadas con el comercio, los miembros de la comunidad italiana han diversificado entretanto sus actividades y parecen menos concentrados en el sector agrícola de lo que estaban anteriormente.

En fin, las “otras actividades” han ganado mucho en complejidad y merecen un análisis más minucioso que nos proponemos abordar en un futuro próximo. 
Volviendo a la agricultura, en 1869 los nativos eran quienes dominaban la cría de ganado, los argentinos eran 43 \% de la población y representaban casi el 79 \% de los hacendados y estancieros (cuadro 7). En 1895, es justamente solo entre los que se dedican a la explotación ganadera que los locales han conservado su papel. Ocupan igualmente un lugar de peso en el otro extremo de la escalera social, es decir, entre jornaleros y peones. En efecto, en 1869 estos últimos se repartían equitativamente entre todas las nacionalidades presentes, mientras que en 1895 los argentinos, que eran minoría entre la población, son amplia mayoría en este sector de actividades. Sobre esta cuestión volveremos pronto.

Para el caso de los nativos, probablemente aún más que entre los extranjeros, intuimos que la evolución del campesinado hacia estos sectores relacionados con el comercio, construcción, artesanía y funcionariado se encuentra vinculado con varios factores; por una parte el avance de la alfabetización y el proceso de urbanización creaban nuevas oportunidades laborales para ellos, pero estaría igualmente ligada al proceso de proletarización de los campesinos que avanzaba lento pero inexorable desde varias décadas atrás.

En otro trabajo referido a periodos anteriores (Contente, 2015, parte II; 2017) constatábamos esta transformación de los pequeños propietarios en jornaleros, no solo gracias al análisis de las cifras globales de censos precedentes, sino también, a través de algunos casos concretos de trayectorias familiares en las que los descendientes de propietarios acomodados e influyentes en la primera mitad del siglo XIX se ganaban la vida como jornaleros un par de generaciones más tarde $\underline{14}$.

Pese a que las cifras que nos ofrecen los censos no siempre permiten definir claramente quién trabaja por su cuenta y riesgo y quién en situación de dependencia podemos hacer algunas estimaciones. Si bien está claro que un estanciero o labradorson cuentapropistas y los peones o jornaleros son asalariados, no podemos saber si un pastor, lechero o puestero está cuidando de sus propios animales o trabajando por cuenta de terceros. De ahí que, tal como hicimos para 1869, realizaremos un doble cálculo considerando a todos estos individuos cuyos medios de vida no podemos establecer, ya sea con los patrones, ya con los trabajadores dependientes. Debemos señalar igualmente que para 1895 es probable que algún obrero esté incluido entre los jornaleros o peones, lo que implica un posible sesgo que es técnicamente imposible estimar $\underline{15}$.

Para 1869 estimábamos que había entre 0,4 y 0,7 patrón por dependiente y entre 1,4 y 2,4 dependiente por patrón. En 1895 el censo nos permite establecer que habría entre 0,25 y 0,4 patrón por dependiente y entre 2,3 y 4 dependientes por patrón $\underline{16}$. Sin duda alguna, la realidad está entre las dos estimaciones, pero en cualquiera de los dos casos está claro el proceso que llevaba a la concentración de los medios de producción. En otros términos, a una menor cantidad de explotaciones independientes y a una mayor cantidad de trabajadores asalariados. directamente ligada a la intensidad de las actividades productivas y a la saturación del espacio es más que evidente $\underline{17}$.

Nos concentraremos ahora en los datos de aquellas actividades representativas y que no se prestan a confusión para observarlos desde otra perspectiva, ya no la de las comunidades, sino la de las ocupaciones en sí.

\section{Cuadro 7 - San Vicente, 1869. Ocupaciones de la población activa masculina según los orígenes (en porcentajes)}

\begin{tabular}{|l|c|c|c|c|c|c|c|c|}
\hline & \multicolumn{2}{|c|}{$\begin{array}{c}\text { Hacendado, } \\
\text { estanciero }\end{array}$} & \multicolumn{2}{c|}{$\begin{array}{c}\text { Labrador, } \\
\text { chacarero, } \\
\text { agricultor }\end{array}$} & \multicolumn{2}{|c|}{$\begin{array}{c}\text { Jornaleros y } \\
\text { peones rurales }\end{array}$} & \multicolumn{2}{c|}{$\begin{array}{c}\text { Comercio, } \\
\text { negociante, } \\
\text { mercachifle... }\end{array}$} \\
\hline & 1869 & 1895 & 1869 & 1895 & 1869 & 1895 & 1869 & 1895 \\
\hline Hombres con activ. atribuida & 169 & 124 & 113 & 308 & 572 & 1.526 & 70 & 392 \\
\hline \% de los trabajadores & $14,5 \%$ & 3 & 9,7 & 7,5 & 49,1 & 37,1 & 6 & 9,5 \\
\hline
\end{tabular}




\begin{tabular}{|l|c|c|c|c|c|c|c|c|}
\hline Argentinos & 78,7 & 68,5 & 15 & 26 & 44,4 & 39,2 & 24,3 & 36 \\
\hline Italianos & 1,2 & 6,4 & 62 & 50,3 & 23,9 & 33,3 & 30 & 29,6 \\
\hline Españoles & 5,9 & 16,1 & 6,2 & 10,7 & 11 & 13,5 & 25,7 & 16,3 \\
\hline Franceses & 4,1 & 8,9 & 8,8 & 7,5 & 10,5 & 7,3 & 14,3 & 8,2 \\
\hline Otros orígenes & 3,6 & - & 7 & 5,5 & 10,1 & 6,7 & 5,7 & 9,9 \\
\hline Total: & 100 & 100 & 100 & 100 & 100 & 100 & 100 & 100 \\
\hline
\end{tabular}

Tanto en términos relativos como absolutos hay menos estancieros y hacendados a fines de siglo que los que había 26 años antes. Los labradores han aumentado de manera notable, aunque en menor medida que el comercio, artesanos, etc.

A fines de siglo la cría de ganado sigue siendo una actividad que los argentinos dominan y si bien algunas explotaciones encabezadas por los nativos se han volcado a la producción de cereales, los italianos siguen teniendo un papel destacado en la agricultura.

Estos elementos sugieren que la orientación productiva se ha modificado en al menos dos direcciones, por un lado, por el avance del proceso de urbanización ya mencionado, por otro, el cultivo de la tierra habría pasado a predominar sobre la cría de ganado e incluso, dentro del ámbito de la cría de ganado, la cría extensiva está dando paso a otro tipo de actividades como la producción de leche y productos derivados. Esta transformación (que cabe confirmar a través de otras fuentes, por ejemplo, fiscales) $\frac{18}{2}$ sería coherente con la evolución que se verifica en las exportaciones argentinas, en las que los cereales han comenzado a superar a los bovinos.

Hemos incluido la distribución por nacionalidades de comerciantes y vendedores, aunque dado el escaso número de efectivos en 1869, las posibilidades de comparación entre ambos son limitadas. En la ciudad de Buenos Aires, españoles e italianos se dedicaban en buena medida al comercio (Arroyo Abad y Sánchez Alonso, 2015, p. 15). José Moya (1998, pp. 219-225) destaca que compartir el idioma daba ventaja a los españoles para desempeñarse en el comercio o en actividades burocráticas, mientras los italianos, si bien también tenían un papel destacado en el comercio, tendían a especializarse en tareas artesanales en las que el dominio del idioma no representaba una barrera insalvable.

Esta tendencia se verifica parcialmente en San Vicente, al menos en lo que respecta a las actividades artesanales y el comercio, aunque los nativos también tenían un papel destacado en esta actividad, lo que es lógico, dada la importancia que podían alcanzar las relaciones y la inserción social del individuo para llevar adelante actividades comerciales. En las décadas anteriores, en cambio, eran españoles y franceses quienes habían tenido una mayor participación en este sector.

Lo notable es que, en 1895, dentro del grupo de situación más precaria del mundo del trabajo -el de los jornaleros-, los argentinos tuvieran tanto peso, ya que siendo el 36,5 \% de los hombres que declaran una ocupación eran algo más del 39 \% de esta categoría, mientras que los extranjeros cuentan proporciones más cercanas o incluso un porcentaje de jornaleros inferior al de sus connacionales dentro del conjunto de los trabajadores, tal como era el caso entre los franceses $\underline{19}$.

Otro elemento que los censos ponen a nuestro alcance es la alfabetización, que en este caso nos ayudará a definir el perfil de los peones y jornaleros. En el lapso transcurrido entre 1869 y 1895, los progresos en ese sentido son evidentes, si en 1869 solo un 36 \% de los argentinos de San Vicente declaraban saber leer y escribir (frente al 50 $\%$ de los hombres y mujeres europeos) (Contente, 2017), en 1895, los hombres y mujeres argentinos que cuentan con esa capacidad en las zonas estudiadas representan el $73 \%$, lo que los hace incluso proporcionalmente más numerosos que el conjunto de los italianos, franceses y españoles (62 \%). Sin embargo, esta proporción conoce importantes $-\mathrm{y}$ previsibles- contrastes entre diferentes sectores; si entre hacendados y labradores nativos $\underline{20}$ los que saben leer y escribir en 1895 superan el 77 \%, entre peones y jornaleros, esta proporción cae a un 54 \% entre 
los argentinos, mientras que entre los extranjeros se acerca al promedio del grupo con un 60 \%.

Nuestra hipótesis es que probablemente para muchos extranjeros el trabajo como jornalero tendía a ser una solución temporaria hasta hacerse un lugar en la sociedad local gracias al oficio que trajeran de sus tierras natales o a las oportunidades que se les brindaran. En este sentido, la antigüedad del flujo migratorio y el tiempo que cada uno de ellos concretamente llevara en el lugar tendría una influencia directa en cuanto a las ocasiones para desarrollar y consolidar redes de sociabilidad con las consiguientes posibilidades de beneficiarse de informaciones a propósito de oportunidades laborales. Por una parte, los migrantes traían a menudo de sus tierras de origen, un oficio susceptible de facilitarles la inserción laboral, por otra, los artesanos migrantes tendían espontáneamente a adoptar como aprendices a sus connacionales o parientes (Arroyo Abad y Sanchez Alonso, 2015, p. 16). En 1895, por ejemplo, 83 \% de los albañiles eran italianos y la totalidad de los peón de albañil que registra el censo (9 individuos) también lo son. Esta preferencia por los connacionales entre los patrones inmigrantes, o por contratar individuos de alguna nacionalidad precisa en función de supuestas habilidades particulares es algo bien conocido igualmente para las tareas rurales (Sabato, 1989, pp. 99-103).

A fines del siglo XIX, para una fracción de los nativos, ganarse la vida como jornaleros representaba muy probablemente la única opción disponible; en otros términos, se iban cerrando oportunidades para ellos. Volveremos más adelante sobre esta cuestión.

Una de las actividades rurales que se ha desarrollado de manera notable entre las dos fechas es la producción lechera. En 1869 hay solo dos tamberos, en 1895 son 115 hombres los que declaran ese oficio: 46 de ellos son franceses y 39 españoles y según se puede intuir a través de los apellidos; muy probablemente muchos de ellos sean vascos (Moya, 1999; Iriani, 1999). Los argentinos en este oficio son minoría entre los productores (17) y mayoría entre los peones (casi un peón de tambo cada dos es argentino). Estos tambos sin duda están relacionados con la producción de quesos: el oficio de quesero también hace su aparición para fin de siglo en la zona y son igualmente extranjeros quienes lo declaran como actividad.

Otro sector de actividad en el que destacan los migrantes es, como decíamos al principio, el de la construcción. De los 161 albañiles, 133 son italianos, así como todos peones de albañil registrados; 20 de los 36 herreros son igualmente italianos y, ya en otros ámbitos, los 7 peluqueros son italianos, 31 de los 43 zapateros, 19 de los 23 sastres... En fin, mientras que españoles y franceses están presentes en un amplio espectro de actividades comerciales, rurales y artesanales, la comunidad italiana se ha especializado, tal como se detecta en la ciudad de Buenos Aires (Moya, 1998, pp. 219-222) en sectores precisos como las actividades artesanales.

\section{Consideraciones finales}

En esta primera aproximación a la evolución que conoció San Vicente en la segunda mitad del siglo XIX, y al papel que la migración jugó al respecto, hemos visto que, ante todo, la zona está sufriendo una transformación con múltiples facetas.

Las tareas rurales están perdiendo protagonismo en beneficio de nuevas actividades propias de zonas urbanas como las profesionales o comerciales. A su vez, en el interior del sector rural se delinean diversas tendencias; por una parte, varios de los productores de ganado -que predominaban en la zona a mediados de siglo- han reorientado sus actividades hacia el cultivo de la tierra. Por otra parte, la ganadería apunta, a fines de siglo, a un modelo en el que la cría extensiva va cediendo paso a la producción de leche y productos derivados.

Y si bien esa conversión hacia el cultivo de cereales está probablemente pautada por la demanda internacional - $\mathrm{y}$ la producción lechera lo está por la demanda de la ciudad-, en todas esas transformaciones y en la capacidad de la región para adaptarse a esa demanda, los migrantes han tenido una participación activa que hemos comprobado a través de la participación de franceses y españoles entre los tamberos, los italianos en la agricultura, etc. Más allá de estos aspectos, la profusión de profesiones como las mencionadas, vinculadas a la construcción (herreros, carpinteros, etc.), a menudo prácticamente monopolizadas por extranjeros, están reforzando desde otra perspectiva 
la evidencia del fuerte crecimiento que atraviesa la región en ese momento. En otras palabras, es una sociedad que está viviendo una transformación profunda y a un ritmo vertiginoso, y en esta transformación, si bien el alud migratorio no representa el único factor que impulsa los cambios, sin duda tuvo un papel decisivo.

Sabemos que en el caso de los EEUU la migración masiva tuvo un impacto negativo para un sector de la población local en lo que respecta a oportunidades de trabajo y salarios (Arroyo Abad y Sánchez Alonso, 2015). El mundo rural bonaerense, en cambio, registró durante este periodo, pese a las oscilaciones, una tendencia general al aumento de los salarios reales (Cortés Conde, 1979, cap. IV; Sabato, 1989, cap. III; Cuesta, 2012). Aunque no podemos saber si los inmigrantes percibían mejores salarios que los locales, sí está bien establecido que gozaban de mayores oportunidades para progresar, que a menudo se los prefería para determinadas tareas. Esto creó sin duda tensiones y estuvo estrechamente vinculado a acciones xenófobas como la del Tata Dios, analizada por Juan José Santos (2012).

En fin, si para los recién llegados la instalación en la campaña bonaerense significaba una promesa de progreso y ascenso social, para buena parte de los locales la llegada masiva de migrantes aceleró el proceso de proletarización que venían sufriendo desde las décadas anteriores.

Mientras una parte de los argentinos, aquellos alfabetizados y con una mejor inserción social, se benefició con el proceso de formación y consolidación del estado y quedó en mejor posición para actividades que requerían el dominio del castellano y el conocimiento de las instituciones y sus instancias -como los empleados públicos-, la contracara fue que para otros, para aquellos pertenecientes a las clases subalternas, las posibilidades de aprender un oficio o de instalarse como pequeños productores independientes se vieron aún más limitadas. A esto se agrega otro aspecto; en un trabajo anterior habíamos comprobado cómo se había complicado para algunos argentinos encontrar esposa ante la migración y la consecuente "sobreoferta" de hombres que representaban potenciales "buenos partidos" (Contente, 2014); este es otro de los factores del proceso que va llevando a la marginación de muchos hombres nativos. Una esposa representa la posibilidad de instalarse, de ser al menos puestero, quizás en zonas más alejadas de Buenos Aires y sometidas a una menor densidad demográfica. Los censos no mencionan el color de piel, que sin duda tendía a ser más oscura entre los locales, de modo que, al ser mestizo, sin oficio, quizás sabiendo apenas leer y escribir y sin poseer ningún otro bien más que sus brazos para trabajar, un nativo tendría escasas posibilidades de conseguir una esposa en un mercado matrimonial ya de por sí desfavorable. Muchos pasarían su vida solteros, saltando de un conchabo a otro como peón o jornalero, subsistiendo con lo justo, con ínfimas posibilidades de salir de su situación. Muy probablemente se da origen así a la arraigada reputación de vagancia, pocas luces y aún menos ambiciones que las clases acomodadas atribuyen hoy en día a los sectores más pobres. Muy probablemente también se va generando ya desde entonces ese amplio sector de la sociedad argentina actual, marginado y sin mayores perspectivas de progreso.

* Este trabajo ha sido realizado con el apoyo de los proyectos, HAR2015-68183-P; Dentro y fuera: Cambio institucional e integración social y cultural en el Imperio Español contemporáneo, 1550-1950 (Mineco/Feder) y 2014 SGR 1193 (AGAUR). La autora agradece a Arnaud Bringé e Isabelle Séguy (INED, Paris) por la inestimable ayuda y consejos.

\section{Notas}

1 Primer Censo de la República Argentina, verificado los días 15, 16 y 17 de septiembre de 1869, con la dirección de Diego G. De la Fuente, superintendente del Censo. Buenos Aires, Imprenta del Porvenir, 1872, pp. 38-45.

$\underline{2}$ Registro Estadístico de la Provincia de Buenos Aires. 1869, Publicación Oficial, Buenos Aires.

$\underline{3}$ Hemos excluido del cálculo a 55 individuos en San Vicente y 25 en Almirante Brown cuyo origen no está especificado por el censo. 
4 Que se repartían de la siguiente manera:

San Vicente 1869 San Vicente 1895 Almte. Brown 1895

Hombres mujeres Hombres mujeres Hombres mujeres Argentinos1.5061.6922.6642.6751.5801.832

Extranjeros 8212301.4635931 .443 856Origen desconocido 282017

10Total2.3271.9224.1553.2883.0402.698

$\underline{5}$ Y si nos centramos en la fracción de la población potencialmente activa (mayores de 14 años) exclusivamente, el índice de masculinidad era de 74,6 entre los nativos y de 356,4 entre los migrantes

6 6 A propósito de la inserción en la sociedad local a través del matrimonio, ver Miguez et al. (1991); Otero (1990; 1991); Silberstein (1991); Otero (2006, pp. 142-149).

Z La población total de San Vicente y Almirante Brown en 1895 incluye 60 personas de sexo indeterminado. Para considerar los mayores de 14 años de 1895 hemos excluido aquellos cuya edad no fue registrada.

$\underline{8}$ Debemos aclarar que para el análisis de las ocupaciones, hemos suprimido del censo de San Vicente de 1869 dos libretas, las 3 y la 23, dado que el censista a menudo atribuyó la misma actividad a todos los miembros de la unidad, (hay por ejemplo, niños pequeños “estancieros" o "labradores”) de modo que no podemos estar seguros de quienes componían efectivamente la fuerza de trabajo de la unidad.

9 A propósito de la urbanización en los diferentes partidos de la campaña bonaerense según fuentes fiscales consultar Gelman y Santilli (2011)

10 En la zona urbana había instalados un par de médicos y curanderos, varios maestros, un escribano, un escribiente y cantidad de artesanos como por ejemplo un alpargatero, sastres, un peinetero y varios hojalateros (Contente Barcos, 2016; Contente -en prensa-)

11 Se cuentan 166 albañiles, 102 carpinteros y 39 herreros

12 Aunque debido a la crisis que se produjo entre 1890-94, la llegada de migrantes disminuyó y algunos regresaron a sus países de origen. A propósito de los retornos ver por ejemplo Cacopardo y Moreno (1985) para los italianos o Moya (1998) respecto a la comunidad española

13 A fin de simplificar las estimaciones hemos reunido peones y jornaleros en un mismo rubro. Todo parece indicar que los términos de peones y jornaleros no significaban lo mismo y que el empleo de uno y otro era según fueran parte del personal estable de una explotación o fueran contratados por lapsos más breves en función de una especialidad o necesidad concreta (Gelman y Santilli, 2014). Sin embargo, en el censo de 1869 algunos censistas parecen hacer la distinción entre ambos alternando ambas categorías, otros inscriben solo peones o solo jornaleros, lo que sugiere que no todos tenían presente una diferencia conceptual entre ambas denominaciones.

14 Hilda Sabato señala asimismo que entre las décadas de1850 y 1880 la expansión de la ganadería ovina significó que fuera cada vez más difícil ganarse la vida de manera autónoma (Sabato 1989, pp. 116-117).

15 La ocupación obrero no fue considerada dentro de la grilla de actividades económicas de 1895 (Otero 2006, pp. 258, 296).

16 En el grupo peones hemos incluido jornaleros y peones de chacra y agrícolas, pero no otras categorías de peones, como de tambo ya que los tamberos no han sido contabilizados entre los propietarios.

$\underline{17}$ El censo de 1815, al delimitar las unidades y permitirnos saber así quién es mano de obra contratada y dónde, es bastante preciso al respecto y nos permite afirmar que, en ese entonces, 600 labradores y criadores se repartían 396 peones y 322 criados (718 dependientes en total en unidades censales de labradores y estancieros), lo que representa 1,2 peones por patrón o 0,8 patrón por peón. 
18 Podría ser igualmente consecuencia de una fuerte concentración de explotaciones dedicadas a la cría de ganado, hipótesis que nos parece menos plausible pero que corresponde igualmente comprobar.

$\underline{19}$ Si retomamos las cifras presentadas en los cuadros 6 y 7, los italianos son 34,1 \% de los trabajadores y 33,3 \% de los jornaleros, los españoles 13,1 \% y 13,3 mientras que los franceses 10,2 y 7,5.

$\underline{20}$ El número de extranjeros no es lo suficientemente significativo como para avanzar porcentajes

\section{Referencias}

\section{Fuentes}

Primer Censo de la República Argentina. Verificado en los días 15, 16 y 17 de Setiembre de 1869 (1872), Imprenta del Porvenir, Buenos Aires.

Segundo Censo de la República Argentina. Mayo 10 de 1895 (1898), Taller Tipográfico de la Penitenciaría Nacional, Buenos Aires.

Registro Estadístico de la Provincia de Buenos Aires. 1869. Publicación Oficial, Buenos Aires.

\section{Bibliografía}

Arroyo Abad, L., y Sánchez- Alonso, B. (2015). A city of trades: Spanish and Italian Immigrants in Late Nineteenth Century Buenos Aires. Argentina. EHES, Working Paper No. 88.

Barsky, O., y Gelman, J. (2001). Historia del agro argentino. Desde la conquista hasta fines del siglo XX. Buenos Aires: Grijalbo Mondadori.

Cacopardo, M. C., y Moreno, J. L. (1985). Características regionales, demográficas y ocupacionales de la inmigración italiana a la Argentina (1880-1930). En F. Devoto y G. Rosoli, (eds.), La inmigración italiana a la Argentina (pp. 63-93). Buenos Aires: Biblos.

Canedo, M. (2000). Propietarios, ocupantes y pobladores. San Nicolás de los Arroyos, 1600-1860. Mar del Plata: Grupo de Investigación en Historia Rural Rioplatense-Universidad de Mar del Plata.

Ceva, M. (2012). El ciclo de la inmigración. En H. Otero (dir.), Historia de la Provincia de Buenos Aires. Tomo 1, Población, ambiente y territorio (pp. 309-336). Buenos Aires: Unipe/ Edhasa.

Contente, C. (2010). Percevoir l'invisible : le travail des femmes à la campagne de Buenos Aires du XIXème siècle à partir du recensement de 1869. En M.P. Arrizabalaga, I. Bolovan, E. Eppel, J. Kok \& M. L. Nagata (coord.), Many Paths to Happiness? Studies in Population and Family History. A Festschrift for Antoinette Fauve-Chamoux (pp. 81-95). Amsterdam: Aksant Publishers.

Contente, C. (2014). Some considerations about the marriage market for migrants in Almirante Brown (Buenos Aires, Argentina) at the end of the nineteenth century. En L. Dumănescu, D. Mârza, M. Eppel, (Eds.), Marriage through History (pp. 451-467). Newcastle upon Tyne: Cambridge Scholar Publishing.

Contente, C. (2017). De los números a las personas. Los habitantes de San Vicente (Buenos Aires) según el Primer Censo Nacional Argentino (1869). Revista de Indias, 2(269), 199-238. DOI: http://dx.doi.org/10.3989/revindias.2017.00

Contente, C., y Barcos, M. F. (2015). La parte sumergida del iceberg. Mujeres trabajadoras en la campaña de Buenos Aires (Argentina) según el Primer Censo Nacional de Población de 1869. En T. M. Ortega López (ed.), Jornaleras, Campesinas y Agricultoras. La Historia Agraria desde una perspectiva de género (pp. 81-109). Zaragoza: Prensas Universitarias de Zaragoza. 
Contente, C., y Barcos, M.F. (2016). Un mundo rural en transición. La campaña bonaerense según el Primer Censo Nacional de Población de la República Argentina (1869). Quinto Sol, 20(1), 1-32. DOI: http://dx.doi.org/10.19137/qs0865.

Cuesta, M. E. (2012). Precios y salarios en Buenos Aires durante la Gran Expansión (1850-1914). Revista de Instituciones, Ideas y Mercados, 56, 159-179.

Cortés Conde, R. (1979). El progreso argentino 1880-1914. Buenos Aires: Editorial Sudamericana.

Gelman, J., y Santilli, D. (2011). ¿Cómo explicar la creciente desigualdad? La propiedad de la tierra en Buenos Aires entre 1839 y 1867. En J. Gelman (comp.), El mapa de la desigualdad en la Argentina del siglo XIX (pp. 171-217). Rosario: Prohistoria.

Gelman, J., y Santilli, D. (2014). Los salarios y la desigualdad en Buenos Aires, 1810-1870. América Latina en la Historia Económica, 21(3), 83-115. DOI: https://doi.org/10.18232/alhe.v21i3.579.

GIHRR (2004). La sociedad rural bonaerense a principios del siglo XIX. Un análisis a partir de las categorías ocupacionales. En R. O. Fradkin, J. C. Garavaglia (eds.), En busca de un tiempo perdido. La economía de Buenos Aires en el país de la abundancia 1750-1865 (pp. 21-63). Buenos Aires: Prometeo, 2004.

González Lebrero, R. E. (2002). La pequeña aldea. Sociedad y economía en Buenos Aires (1580-1640). Buenos Aires: Editorial Biblos.

Hora, R. (2010). Historia económica de la Argentina en el siglo XIX. Buenos Aires: Siglo Veintiuno Editores.

Hora, R. (2012). La evolución de sector agroexportador argentino en el largo plazo, 1880-2010. Historia Agraria 58, Murcia-Zaragoza, 145-181.

Iriani, M. (1999). ¿Buscar trabajo o buscar un trabajo? Los vascos en la Provincia de Buenos Aires en el siglo XIX. En A. E. Fernández y J. C. Moya, La inmigración española en la Argentina (pp. 97-113). Buenos Aires: Biblios.

Lattes, A., y Andrada, G. (2012). La población entre 1870 y 2000. Una dinámica demográfica diferente. En Otero, H. (dir.), Historia de la Provincia de Buenos Aires. Tomo 1: Población, ambiente y territorio (pp.175-209). Buenos Aires: UNIPE- EDHASA.

Levene, R. (1941). Historia de la Provincia de Buenos Aires y de la formación de sus pueblos. La Plata: Archivo Histórico de la Provincia de Buenos Aires.

Massé, G. (2006). Inmigrantes y nativos en la ciudad de Buenos Aires al promediar el siglo XIX. Población de Buenos Aires, 3(004), Dirección General de Estadística y Censos, 9-25.

Massé, G. (2012). El tamaño y el crecimiento de la población desde la Conquista hasta 1870. En H. Otero (dir.), Historia de la Provincia de Buenos Aires. Tomo 1: Población, ambiente y territorio (pp. 143-156). Buenos Aires: UNIPE- EDHASA.

Mateo, J. (1993). Población y producción de un ecosistema agrario de la frontera del Salado (1815-1869). En R. Mandrini y A. Reguera (comps.), Huellas en la tierra. Indios, agricultores y hacendados en la pampa bonaerense (pp. 161-190). Tandil: Instituto de Estudios Histórico-Sociales.

Mateo, J. (2013). La sociedad: población, estructura social y migraciones. En M. Ternavasio (dir.), Historia de la Provincia de Buenos Aires, Tomo III. De la Organización provincial a la federalización de Buenos Aires (18211880) (pp. 73-116). Buenos Aires: Unipe/Edhasa.

Míguez, E. (2008). Historia económica de la Argentina desde la Conquista a la crisis de 1930. Buenos Aires: Editorial Sudamericana. 
Míguez, E., Argeri, M. E., Bjerg, M. M., y Otero, H. (1991). Hasta que la Argentina nos una. Reconsiderando las pautas matrimoniales de los inmigrantes, el crisol de razas y el pluralismo cultural. The Hispanic American Historical Review 71(4), 771- 808.

Moya, J. C. (1998). Cousins and Strangers. Spanish Immigrants in Buenos Aires, 1850-1930. Berkeley: University of California Press.

Moya, J. C. (1999). La “fiebre” de la emigración: el proceso de difusión en el éxodo transatlántico español, 18501930. En A. E. Fernández y J. C. Moya, La inmigración española en la Argentina (pp. 19-41). Buenos Aires: Biblios.

Ortelli, S. (2012). La frontera y el mundo indígena pampeano (1516-1820). En R. Fradkin (dir.), Historia de la Provincia de Buenos Aires, Tomo II, Buenos Aires de la conquista hasta 1820 (pp. 155-177). Buenos Aires: Unipe/Edhasa.

Otero, H. (1990). Una visión crítica de la endogamia: reflexiones a partir de una reconstrucción de familias francesas, (Tandil, 1850-1914). Estudios Migratorios Latinoamericanos, 15-16, 343-378.

Otero, H. (1991). Patrones diferenciales de nupcialidad en nativos e inmigrantes. Tandil (Buenos Aires), 18501914. Anuario del IEHS, VI, 199-228.

Otero, H. (2006). Estadística y Nación. Una historia conceptual del pensamiento censal de la Argentina Moderna. 1869-1914. Buenos Aires: Prometeo.

Ratto, S. (2003). La frontera bonarense (1810-1828): espacio de conflicto, negociación y convivencia, La Plata: Publicaciones del Archivo Histórico de la Provincia de Buenos Aires. Estudios sobre la Historia y Geografía Histórica de la Provincia de Buenos Aires.

Ratto, S. (2013). La frontera y el mundo indígena. En M. Ternavasio, (dir.), Historia de la Provincia de Buenos Aires, Tomo III. De la Organización provincial a la federalización de Buenos Aires (1821-1880) (pp. 247-268). Buenos Aires: Unipe/Edhasa, 2013.

Rayes, A. (2015). La estadística de las exportaciones argentinas, 1875-1913. Nuevas evidencias e interpretaciones. Investigaciones de Historia Económica - Economic History Research, pp. 31-42. http://dx.doi.org/10.1016/j.ihe.2014.03.015.

Sabato, H. (1989). Capitalismo y ganadería en Buenos Aires: La fiebre del lanar: 1850-1890. Buenos Aires: Editorial Sudamericana.

Santilli, D. (2010). Quilmes. Una historia Social. Quilmes: El Monje Editor.

Santos, J. J. (2012). El tata Dios: Milenarismo y xenofobia en las pampas. Buenos Aires: Penguin Random House.

Schkolnik, S., y Pantalides, E. E. (1974). Los cambios en la composición de la población. En Z. Recchini de Lattes y Lattes, A. (comp.), La Población de Argentina, C.I.C.R.E.D Series, pp. 67-93.

Silberstein, C. (1991). Inmigración y selección matrimonial. El caso de los italianos en Rosario (1870-1910). Estudios migratorios latinoamericanos 6, 18, pp. 161-190. 